\title{
CC. COBENGE \\ ANÁLISE DE DADOS NO ESTUDO DE INDICADORES DE DESEMPENHO E EVASÃO NO CURSO DE ENGENHARIA ELÉTRICA DA UFES
}

DOI: $10.37702 / 2175-957 X . C O B E N G E .2021 .3632$

Tiara Rodrigues Smarssaro de Freitas - tiara.freitas@ufes.br

UFES

Rua Odette de Oliveira Lacourt 1231

29060-050 - Vitória - ES

Thalis Rocha Pestana - rocha.thalis@gmail.com

Universidade Federal do Espírito Santo

Rua José Neves Cypreste 1091

29060-300 - Vitória - ES

Patrick Marques Ciarelli - patrick.ciarelli@ufes.br

Universidade Federal do Espírito Santo

Avenida Eldes Scherrer Souza 2286

29167-080 - Serra - ES

Gabrielly Barcelos Cariman - gabriellycariman@gmail.com Universidade Federal do Espírito Santo

Rua Artacerce Brotto 75

29065-700 - Vitória - ES

Lucas Manfioletti - lucas.manfioletti@gmail.com

Universidade Federal do Espírito Santo

Rua Francisco Martins da Costa 40

29062-570 - Teixeira de Freitas - BA

Gabriel Simões Oliveira - gabrielsimoes.drive@gmail.com

Universidade Federal do Espírito Santo

Rua Vista Mar 293

29143-224 - Cariacica - ES

Resumo: Esse documento apresenta o estudo conduzido pelo grupo PET 
Engenharia Elétrica UFES com o objetivo de obter indicadores para avaliação dos índices de evasão e desempenho acadêmico dos estudantes do curso de Engenharia Elétrica da UFES. Nesse contexto, ferramentas de análises de dado como o Google Colab foram utilizadas. A metodologia de análise e os resultados obtidos estão apresentados, bem como as conclusões sobre o perfil acadêmico observado.

Palavras-chave: Taxa de evasão. Desempenho acadêmico. Análise de dados. Ferramentas digitais 


\section{ANÁLISE DE DADOS NO ESTUDO DE INDICADORES DE DESEMPENHO E EVASÃO NO CURSO DE ENGENHARIA ELÉTRICA DA UFES}

\section{INTRODUÇÃO}

Historicamente, sabe-se que os índices de evasão no ensino superior, internacionalmente, configuram um sério problema no sistema educacional. No Brasil, esse problema é acentuado pela diferença de condições dos alunos ingressantes, havendo uma certa correlação, embora não muito significativa, entre evasão e fatores socioeconômicos (SILVA FILHO, 2007).

Os cursos brasileiros de Engenharia, mais especificamente, apresentam uma evasão extremamente alta. Através de dados disponibilizados pelo Instituto Nacional de Estudos e Pesquisas Educacionais - INEP, comparando o número de alunos ingressantes e concluintes dos cursos de Engenharia, verificou-se que nas Instituições de Ensino Superior - IES privadas o índice de evasão ultrapassa $60 \%$ enquanto nas públicas ele é pouco maior que 40\% (ALVES, 2017).

Nesse sentido, as ferramentas de programação voltadas para a análise de dados, configuram um poderoso instrumento para a validação de indicadores que possam vir a auxiliar às coordenações/colegiados dos cursos na tomada de decisões, afim de reduzir os prejuízos acadêmicos e sociais advindos das altas taxas de desistência, principalmente, nos cursos de Engenharia.

O Programa de Educação Tutorial possui como uma de suas principais premissas a promoção de iniciativas para melhoria contínua dos cursos de graduação a nível superior, consequentemente, atuando na diminuição dos índices de reprovação e evasão nas universidades públicas. O grupo PET Engenharia Elétrica da Universidade Federal do Espírito Santo - UFES visa, por meio deste trabalho, apresentar uma alternativa de diagnóstico do desempenho acadêmico dos estudantes, possibilitando uma análise mais aprofundada do perfil acadêmico dos mesmos e uma ação mais efetiva para a redução dos altos índices de evasão nos cursos de Engenharia.

Este artigo traz um breve resumo das ferramentas e fundamentos aplicados no intuito de obter indicadores de uma possível correlação entre o desempenho inicial dos alunos na graduação e a continuidade de suas carreiras acadêmicas. Todas as análises foram baseadas nos dados relativos a aprovações e reprovações dos alunos do curso de Engenharia Elétrica da UFES de 2012 até 2019.

\section{METODOLOGIA}

Os dados tratados neste trabalho foram obtidos junto ao colegiado do curso de Engenharia Elétrica e a Superintendência de Tecnologia da Informação da Universidade Federal do Espírito Santo - UFES. Os referidos dados consistem em tabelas contendo matrícula, média final e situação (Aprovado, Reprovado por nota ou Reprovado por frequência) dos alunos dos cursos do Centro Tecnológico, bem como o nome e código da disciplina, além do ano e semestre em que foi cursada. Também se verifica o nome e matrícula do docente responsável.

Objetivando a análise matemática dos dados, utilizou-se a ferramenta Google Colab: ambiente adaptado para Machine Learning, Análise de Dados e Educação que permite à múltiplos usuários a escrita e execução de códigos na linguagem Python, diretamente em um navegador. Em termos técnicos, o Colab é um serviço de hospedagem de notebooks 
que não necessita de nenhuma configuração adicional e permite o acesso gratuito a recursos de informática diversos (GOOGLE, 2020).

O Google Colab utiliza a biblioteca Pandas, uma biblioteca Python para análise de dados, muito utilizada para análise exploratória de dados, permitindo ler, manipular, agregar e plotar os dados com mais facilidade.

\subsection{Metodologia de análise do desempenho acadêmico}

No intuito de realizar uma síntese do desempenho acadêmico dos alunos de Engenharia Elétrica, foram filtradas apenas as médias finais das disciplinas de interesse e, posteriormente, separadas em três grupos. Os métodos gráficos: histograma e box plot foram utilizados, objetivando uma análise visual das variáveis em questão.

Segundo Morettin e Bussab (2004), a representação pelo box plot mostra a dispersão, assimetria, posição central, caudas e dados atípicos, proporcionando uma análise visual mais aprofundada. Conforme o modelo na Figura 1, é composto por: primeiro quartil $(Q 1)$, segundo quartil $(Q 2)$, terceiro quartil $(Q 3)$ e os limites mínimos e máximos dos dados, além dos valores exteriores.

Os quartis são medidas de posição. O primeiro quartil separa os dados em $25 \%$ menores (valores abaixo de $Q 1$ ) e $75 \%$ maiores (valores acima de $Q 1$ ). O segundo quartil é a mediana e descreve o centro da distribuição, enquanto o terceiro quartil separa os dados em $75 \%$ menores (valores abaixo de Q3) e $25 \%$ maiores (valores acima de Q3). Dessa maneira, $50 \%$ dos valores ficam contidos no retângulo delimitado, superior e inferiormente, por $Q 3$ e $Q 1$.

A dispersão é dada pela distância interquartílica $(Q 3-Q 1)$, as posições relativas entre os quartis $Q 1, Q 2$ e $Q 3$ indicam simetria ou assimetria na distribuição dos dados. Os comprimentos das caudas são dados pelas linhas que vão do retângulo aos valores exteriores (outliers). Os valores exteriores são aqueles que se diferenciam drasticamente, quando comparados aos demais valores.

Figura 1 - Esquema de gráfico box plot

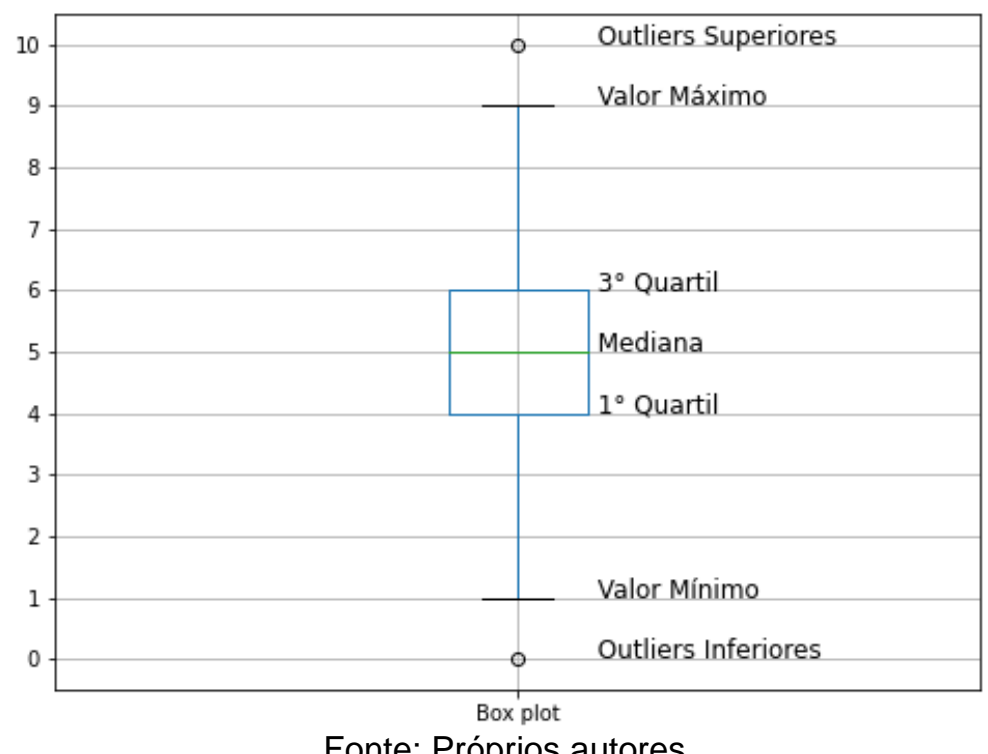

Fonte: Próprios autores.

Utilizando as ferramentas supracitadas, foram filtradas as notas dos alunos nas matérias iniciais: Cálculo I, Cálculo II e Álgebra Linear. Em seguida, os dados filtrados foram divididos em três grupos: o primeiro composto por alunos com pior desempenho, ou seja, 
os que obtiveram média final menor que 5 pontos, o segundo por alunos com desempenho médio, os que obtiveram média final entre 5 e 7 pontos e o terceiro grupo por alunos com melhor desempenho, ou seja, alunos com média final maior que 7. Vale ressaltar que para todos os cursos de graduação da UFES, a aprovação de um aluno em uma determinada disciplina se dá quando a média final do estudante é maior ou igual a 7. Caso contrário o aluno deve realizar a prova final. Nesse caso a média final para aprovação passar a ser 5 .

Em seguida, os dados relativos ao desempenho dos alunos compondo os três grupos acima citados foram cruzados com os dados do desempenho desses mesmos alunos em disciplinas que podem ser realizadas apenas no fim/metade do curso de Engenharia Elétrica: Circuitos Elétricos I, Conversão Eletromecânica de Energia, Máquinas Elétricas e Eletrônica Digital. Desse modo, pretendeu-se observar a influência de um bom/mau desempenho nas matérias iniciais (ou a ausência dessa influência) no desempenho acadêmico dos estudantes da graduação ao decorrer do curso.

\subsection{Metodologia de análise do índice de aprovações/reprovações}

Para a análise do índice de aprovações/reprovações, inicialmente, foram definidas três amostras, a primeira amostra contendo os dados relativos aos alunos reprovados nas disciplinas iniciais do curso (Cálculo I, Cálculo II e Álgebra Linear); a segunda amostra contendo os dados dos alunos aprovados sem reprovações nessas mesmas matérias e a terceira amostra contendo os dados de todos os alunos nas matérias realizadas na metade/fim do curso (Circuitos Elétricos I, Conversão Eletromecânica de Energia, Máquinas Elétricas e Eletrônica Digital).

Em seguida, foram cruzados os dados da primeira e segunda amostra (dados dos alunos reprovados e aprovados sem reprovação nas disciplinas iniciais, respectivamente) com os dados da terceira amostra (dados dos alunos nas disciplinas realizadas na metade/fim do curso). Dessa forma, obtiveram-se os gráficos relacionados a aprovações e reprovações dos alunos da primeira e segunda amostra em disciplinas mais avançadas, ambicionando concluir se existe uma correlação entre um mau/bom desempenho nas disciplinas iniciais e as chances de reprovação ao longo da graduação.

\subsection{Metodologia de análise do índice de desistência}

$\mathrm{Na}$ análise do índice de desistência no curso de Engenharia Elétrica, de forma semelhante a análise de aprovações/reprovações, foram definidas duas amostras de alunos: a primeira amostra, composta de alunos que reprovaram em alguma das matérias iniciais (Cálculo I, Cálculo II e Álgebra Linear), e a segunda amostra composta de alunos que foram aprovados sem nenhuma reprovação nessas disciplinas.

Feita a separação das duas amostras, os dados relativos a cada uma delas foram cruzados com os dados dos semestres posteriores no intuito de verificar se as matrículas continuavam ativas nos três semestres seguintes à reprovação, assim constatando se os alunos haviam desistido ou se permaneciam ativos no curso. A escolha dos três semestres para a validação dos dados deu-se pela possibilidade de trancamento de matrícula por até dois semestres sem justificativa ao colegiado.

Em relação a primeira amostra de alunos, foram selecionados aqueles que constavam como "Reprovado por nota" e "Reprovado por frequência" em cada semestre, de 2012 até 2018. Os dados relativos a 2019 não foram utilizados devido ao fato de não existirem dados dos anos seguintes, não sendo possível definir se houve realmente a desistência de um aluno que ingressou no curso de Engenharia Elétrica da UFES nesse ano. 


\section{3}

RESULTADOS

\subsection{Análise de desempenho acadêmico}

Os histogramas foram produzidos com o mesmo número de colunas (bins), que possuíam o mesmo tamanho na intenção de realizar uma análise comparativa. A Figura 2 apresenta o histograma das notas nas disciplinas mais avançadas dos alunos que tiveram o pior desempenho nas matérias iniciais.

Figura 2 - Histograma dos alunos com pior desempenho nas matérias iniciais do curso

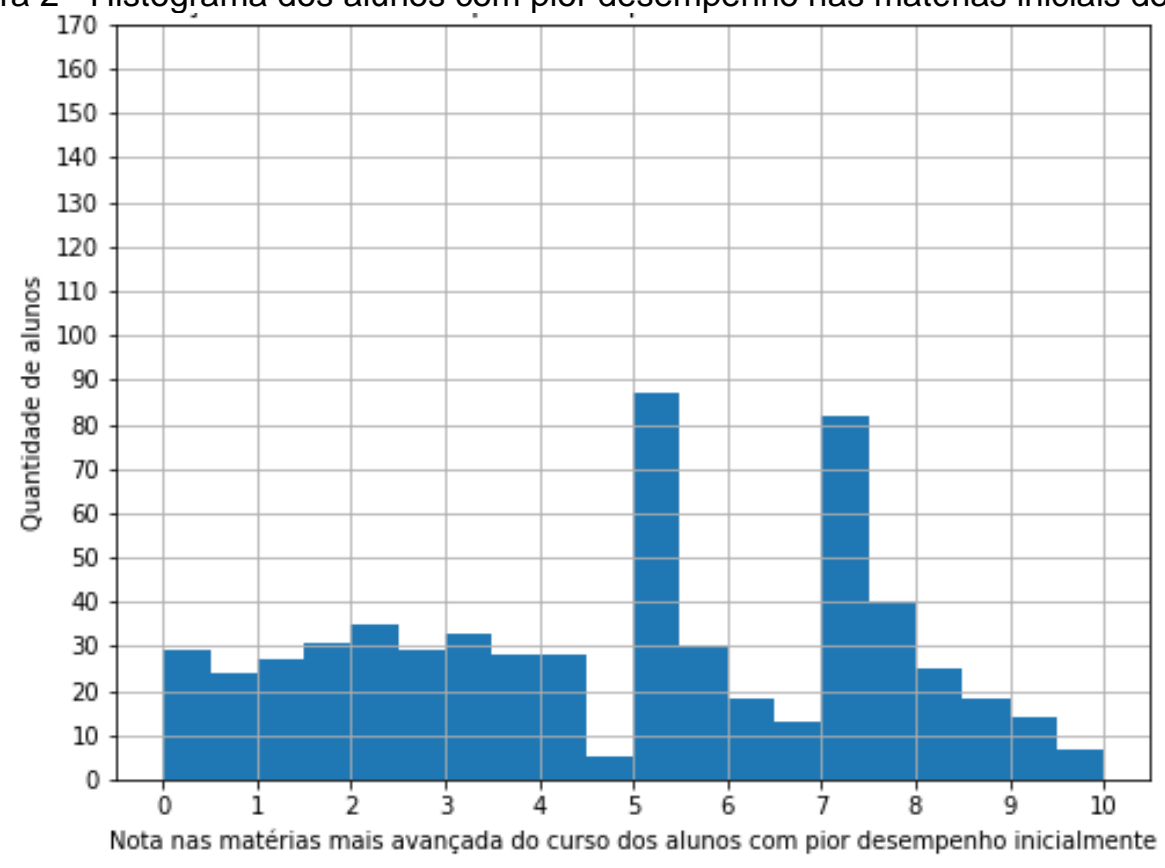

Fonte: Próprios autores.

Observa-se uma distribuição de médias bastante uniforme, havendo uma leve predominância de médias finais entre 5-6 e 7-8.

A Figura 3 mostra o histograma das notas nas disciplinas mais avançadas dos alunos que tiveram o desempenho médio nas matérias iniciais.

Figura 3 - Histograma dos alunos com desempenho médio nas matérias iniciais do curso 


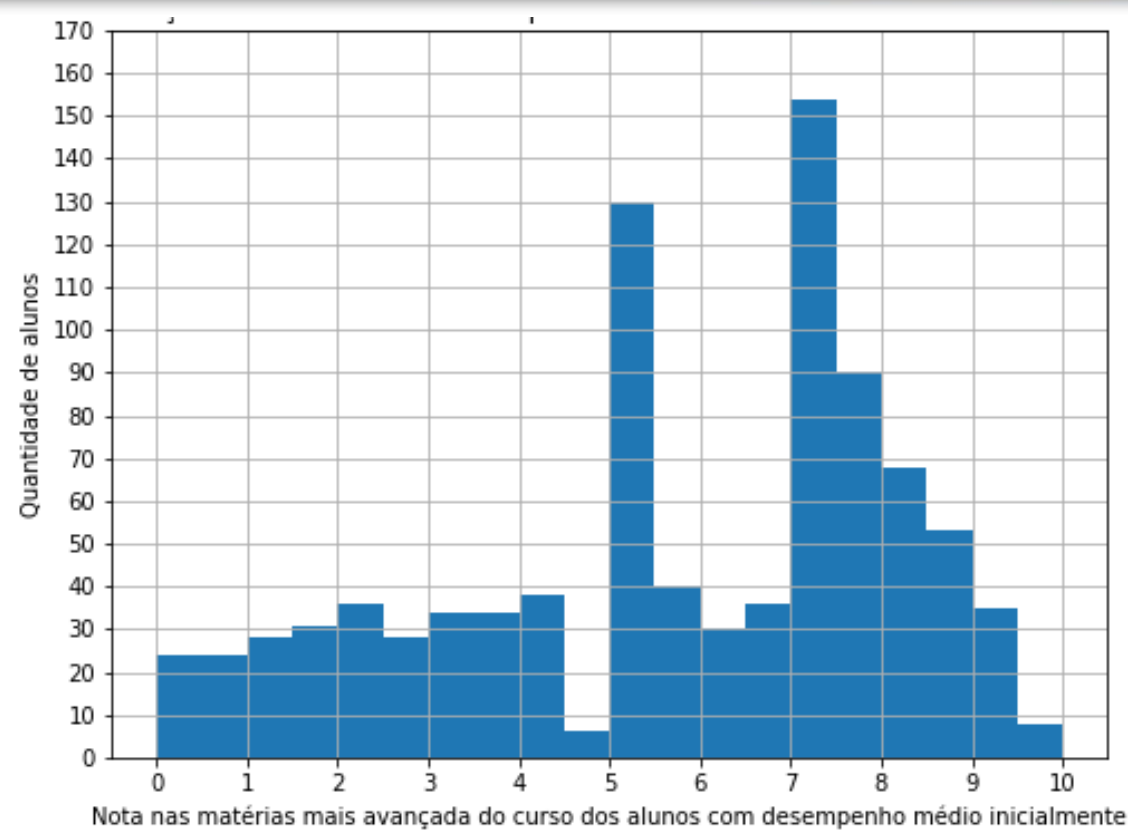

Fonte: Próprios autores.

A Figura 4 mostra o histograma das notas nas disciplinas mais avançadas dos alunos que tiveram o melhor desempenho nas matérias iniciais.

Figura 4 - Histograma dos alunos com melhor desempenho nas matérias iniciais do curso

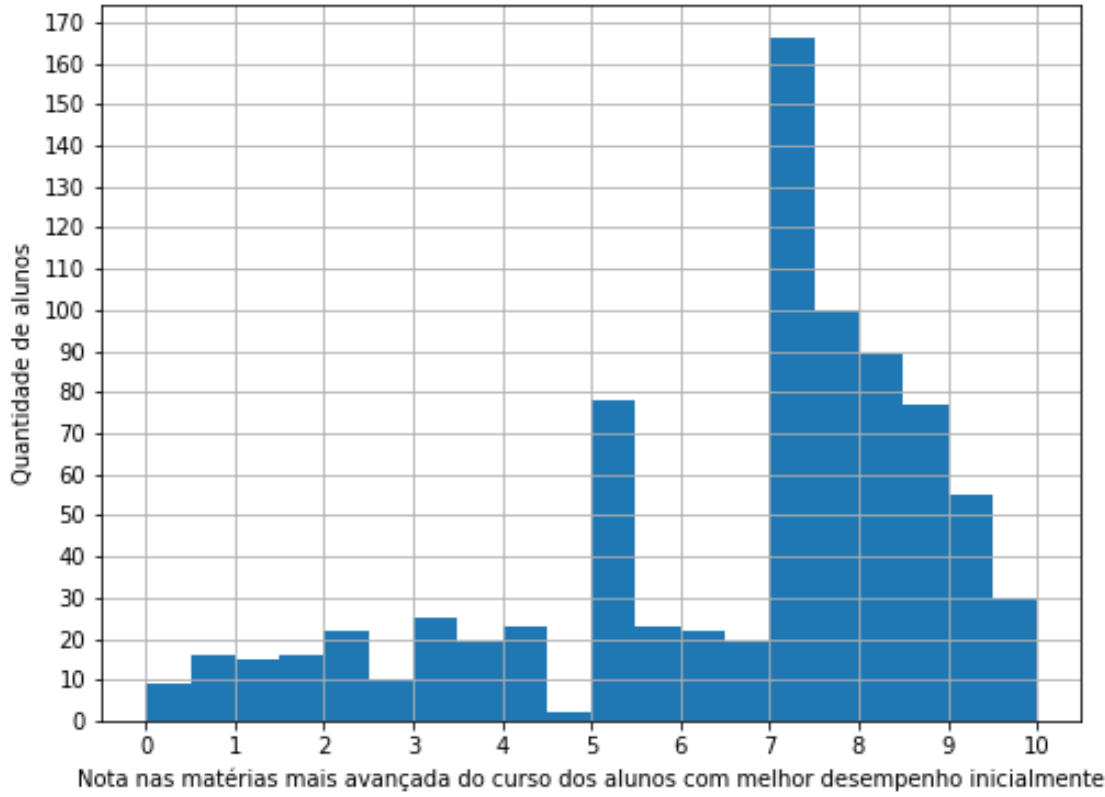

Fonte: Próprios autores.

Nos histogramas das Figuras 3 e 4, é possível identificar uma predominância evidente de médias finais superiores a 7 . tópico.

Por fim, na Figura 5, nota-se um box plot de todas as variáveis analisadas neste

Figura 5 - Box plot das médias finais de todos os grupos 


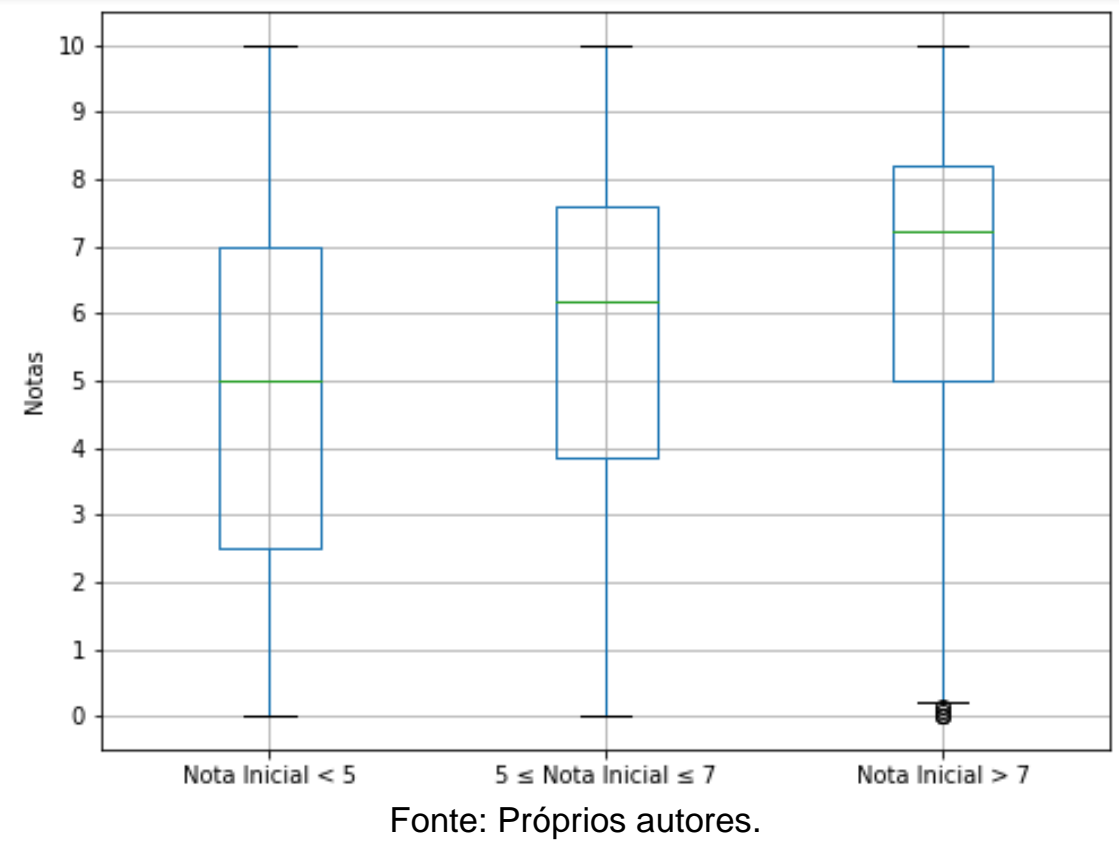

A partir da análise da Figura 5, torna-se possível verificar a distribuição das notas em cada grupo, com o pior desempenho inicial, com o desempenho inicial médio e com o melhor desempenho inicial. O grupo com o pior desempenho inicial é o de maior dispersão, indicado pela maior distância entre o terceiro e primeiro quartil. Por outro lado, o grupo com melhor desempenho inicial é o de menor dispersão e o único que tem uma distribuição assimétrica com outliers em zero aproximadamente.

\subsection{Análise do índice de aprovações}

Em relação a análise das aprovações, após implementadas as funções, dentre as 625 matrículas em que constava a situação "Reprovado por Nota" ou "Reprovado por Frequência", ao menos uma vez, nas matérias iniciais do curso, verificou-se 338 aprovações, 237 reprovações por nota e 50 reprovações por frequência nas matérias mais avançadas, como é possível observar na Figura 6.

Figura 6 - Aprovações e reprovações entre os alunos que apresentaram reprovação ao menos uma vez nas matérias iniciais do curso de Engenharia Elétrica 


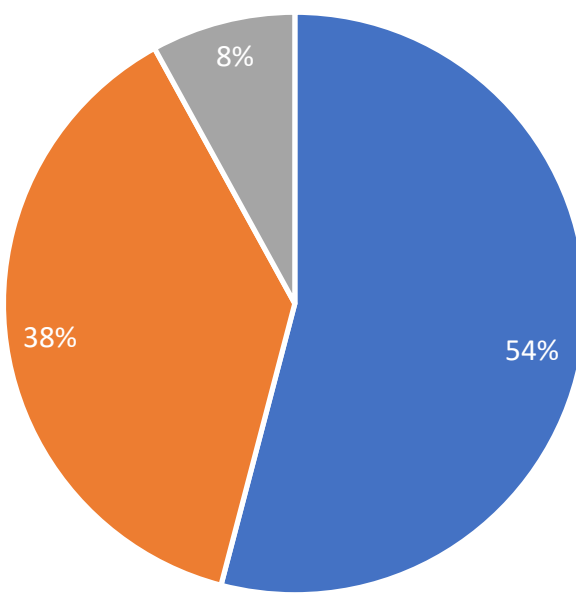

- Aprovado Reprovado por Nota I Reprovado por Frequencia

Fonte: Próprios autores

Entre as matrículas que apresentavam a situação "Aprovado", de forma direta, ou seja, sem nenhuma reprovação nas matérias iniciais do curso, foram registradas nas matérias avançadas 210 aprovações, 39 reprovações por nota e 11 reprovações por frequência, conforme a Figura 7.

Figura 7 - Aprovações e reprovações entre os alunos aprovados de forma direta nas matérias iniciais do curso de Engenharia Elétrica

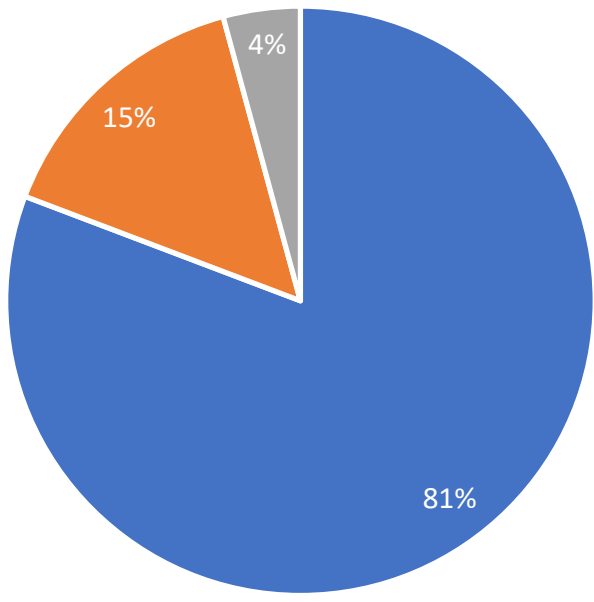

- Aprovado - Reprovado por Nota - Reprovado por Frequencia

Fonte: Próprios autores

Ao realizar uma breve análise dos gráficos das Figuras 6 e 7, é possível observar que entre os alunos aprovados diretamente nas matérias iniciais o índice de aprovação nas 
matérias mais a frente é, nitidamente, maior do que aquele observado entre os alunos com reprovações nas disciplinas ministradas nos primeiros períodos do curso.

\subsection{Análise de índice de desistência}

Em relação a análise da desistência entre os alunos com reprovações nas matérias iniciais, observou-se o perfil descrito na Figura 8.

Figura 8 - Comparação dos alunos reprovados (amostra de 509 alunos)

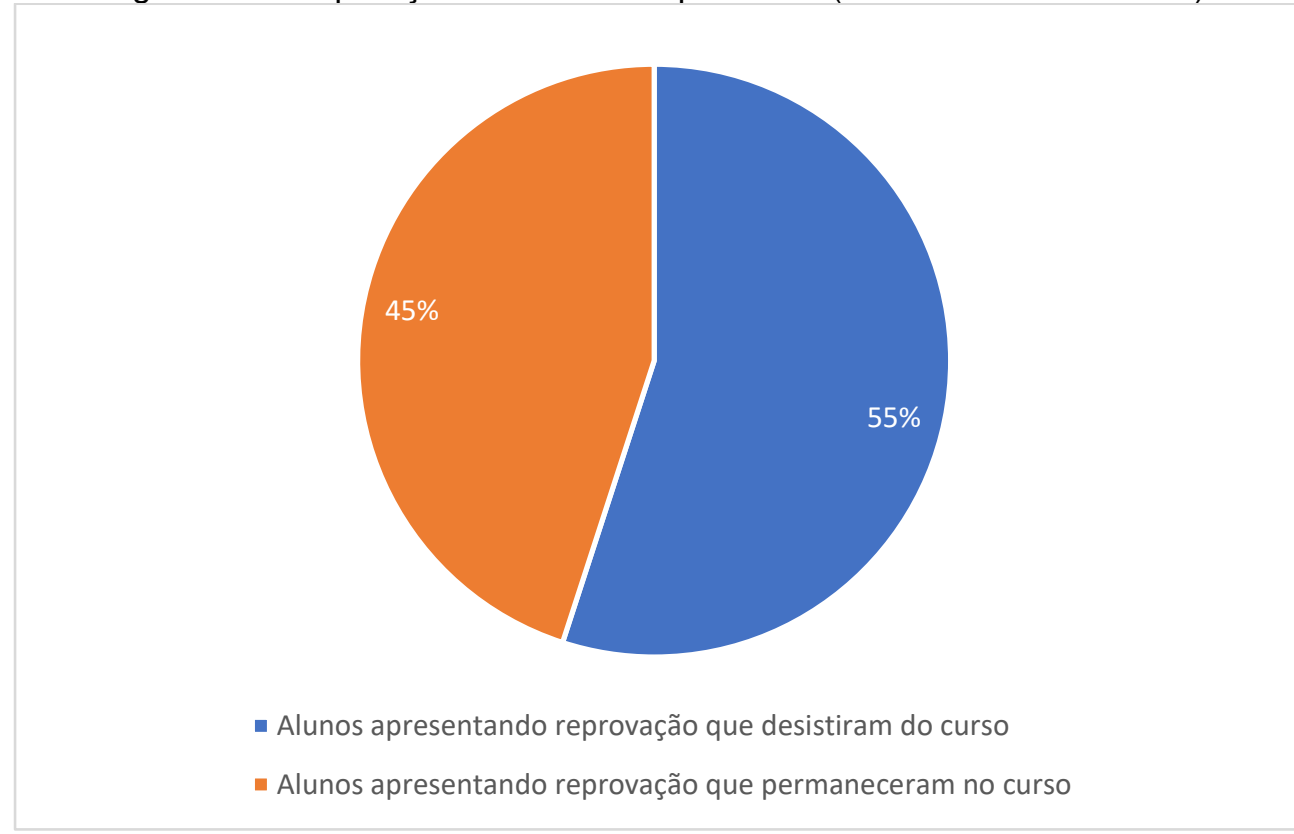

Fonte: Próprios autores.

No gráfico comparativo entre os aprovados de forma direta nas matérias iniciais, desistentes e não desistentes, a porcentagem de desistentes é levemente superior à de não desistentes, como pode ser observado na Figura 9.

Figura 9 - Comparação dos alunos aprovados (amostra de 447 alunos)

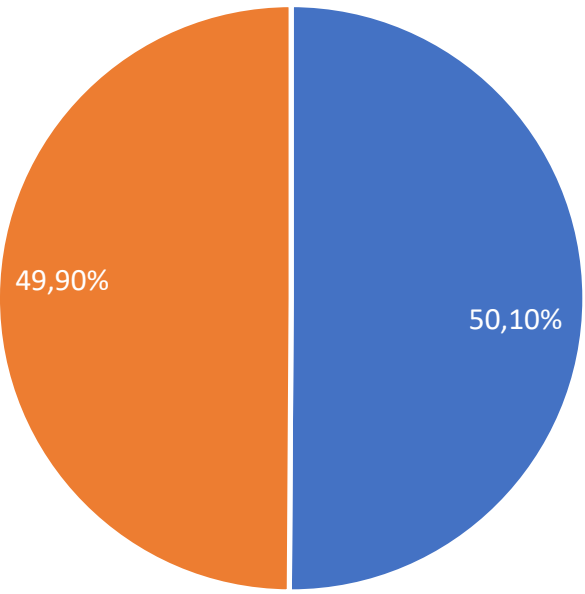

- Alunos aprovados diretamente que desistiram do curso

- Alunos aprovados diretamente que permaneceram no curso

Fonte: Próprios autores. 
Por fim, avaliou-se a desistência entre os alunos reprovados e aprovados nas disciplinas iniciais, conforme a Figura 10.

Figura 10 - Comparação dos alunos desistentes

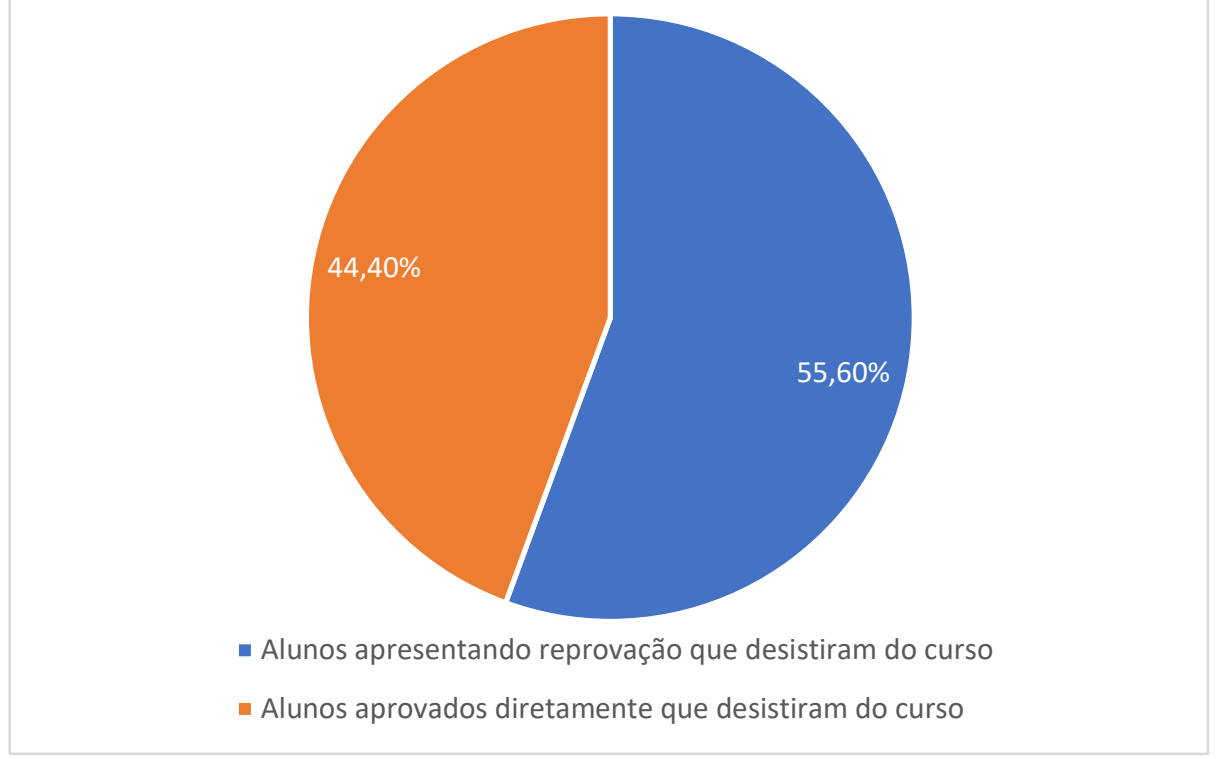

Fonte: Próprios autores.

Verifica-se uma leve predominância do índice de evasão entre aqueles que tiveram pior desempenho inicial.

\section{CONSIDERAÇÕES FINAIS}

Analisando os resultados obtidos, concentrando-se sobre os histogramas das Figuras 2, 3 e 4, nota-se que o histograma dos alunos com médio e alto desempenho nas disciplinas inaugurais possuem perfis muito semelhantes. Percebe-se que na maioria dos casos os estudantes tendem a manter o alto desempenho ao longo do curso. Os histogramas dos alunos de médio e alto desempenho inaugural apresentam uma forte tendência de médias altas no decorrer da formação. Essa tendência não é observada no histograma dos alunos com pior desempenho inaugural. Nesse caso, percebe-se um histograma mais espaçado e uma leve predominância de médias entre 5-6 e 7-8, porém, essa predominância não é evidente.

Observando o box plot da Figura 5, nota-se que a distribuição de todas as médias finais dos estudantes de desempenho alto nas disciplinas inaugurais do curso tem mediana de 7,25 pontos, superior à dos alunos com médio e baixo desempenho, 6,17 e 5, respectivamente. Também pode-se perceber, pela divisão dos quartis, que entre os alunos que obtiveram melhor média nas disciplinas iniciais, pelo menos $75 \%$ mantiveram uma média final superior a 5 nas matérias seguintes.

O grupo com desempenho inicial intermediário permaneceu com médias finais intermediárias nas disciplinas posteriores, apresentando mediana de 6,17 pontos e pouco mais da metade desses alunos apresentaram média final superior a 6 nas disciplinas subsequentes. Por fim, o grupo que apresentou desempenho inferior nas disciplinas iniciais continuou com o pior desempenho: mediana igual a 5,00 e 50\% das médias finais abaixo de 5,00 pontos. 
Observando os índices de reprovações e aprovações, constata-se novamente uma tendência clara. Entre os alunos que apresentaram ao menos uma reprovação nas disciplinas inaugurais, o índice de aprovações no decorrer da graduação é, notadamente, menor que o índice de aprovações entre aqueles que foram aprovados diretamente em Cálculo I, Cálculo II e Álgebra Linear (54\% e 81\%, respectivamente).

No que concerne a evasão, observando as Figuras 8 e 9, constatam-se índices de desistência muito semelhantes entre os alunos que apresentaram reprovação e os diretamente aprovados nas disciplinas iniciais quando observados os grupos separadamente. No entanto, na Figura 10 relativa aos índices de evasão entre os alunos reprovados e aprovados comparados diretamente, percebe-se que a evasão é levemente predominante entre os alunos reprovados ao menos uma vez em uma matéria inaugural. Também chama a atenção o fato do índice de evasão da Engenharia Elétrica na UFES ser superior ao índice de evasão obtido através do cruzamento dos dados do INEP para as instituições públicas brasileiras (ALVES, 2017).

Tendo em vista as considerações acima, observa-se uma forte correlação entre o desempenho inicial e a performance posterior dos estudantes da graduação em Engenharia Elétrica da UFES. Consequentemente, mostra-se necessário traçar o perfil dos alunos ingressantes afim de identificar as origens dos problemas acadêmicos e mitigar seus efeitos.

Além disso, os resultados aqui apresentados reforçam a eficácia de ferramentas para análise de dados, como o Google Colab, na identificação de padrões e indicadores que possam vir a potencializar o aperfeiçoamento do ensino superior brasileiro. Nesse sentido, espera-se que as informações aqui contidas possam despertar o interesse e empenho das coordenações dos cursos de graduação, principalmente na UFES, de forma que possam utilizar-se de ferramentas digitais semelhantes no intuito de buscar a raiz dos problemas de desempenho e evasão universitária, podendo, finalmente, reduzi-los.

\section{Agradecimentos}

Agradecemos ao Colegiado do curso de Engenharia Elétrica da UFES e a Superintendência de Tecnologia da Informação pela disponibilização dos dados de imprescindível importância para a realização deste trabalho. Agradecemos também ao MEC e ao FNDE, órgãos de absoluta importância para o suporte estrutural e financeiro do grupo PET Engenharia Elétrica UFES.

\section{REFERÊNCIAS}

ALVES, Marcos Fernando Soares et MANTOVANI, Kátia Luzia. IDENTIFICAÇÃO DO PERFIL DOS ACADÉMICOS DE ENGENHARIA COMO UMA MEDIDA DE COMBATE À EVASÃO. Revista de Ensino de Engenharia, v. 35, n. 2, p. 26-36, 2016.

ARAÚJO, Elisson Alberto Tavares, DE CAMARGOS, Marcos Antônio, CAMARGOS, Mirela Castro Santos, et al. Desempenho Acadêmico de Discentes do Curso de Ciências Contábeis: Uma análise dos seus fatores determinantes em uma IES Privada. Contabilidade Vista \& Revista, v. 24, n. 1, p. 60-83, 2013.

FELICETTI, Vera-Lucia, CABRERA, Alberto F., COSTA-MOROSINI, Marilia. Aluno ProUni: impacto na instituição de educação superior e na sociedade. Revista iberoamericana de educación superior, v. 5, n. 13, p. 21-39, 2014. 
GOOGLE. 0 que é o Colaboratory?. Disponível em: https://colab.research.google.com/notebooks/intro.ipynb. Acesso em: 05 mai. 2021.

MORETTIN, P. A.; BUSSAB, W. O. Estatística Básica. 5. ed. São Paulo: Saraiva, 2004.

SILVA FILHO, Roberto Leal Lobo e et al. A evasão no ensino superior brasileiro. Cad. Pesqui., São Paulo, v. 37, n. 132, p. 641-659, Dezembro, 2007. Disponível em: http://www.scielo.br/scielo.php?script=sci arttext\&pid=S010015742007000300007\&lng=en\&nrm=iso. Acesso em: 05 mai. 2021.

\section{DATA ANALYSIS IN THE STUDY OF PERFORMANCE AND EVASION INDICATORS IN THE UFES ELECTRICAL ENGINEERING COURSE}

Abstract: This document presents the study conducted by the group PET Engenharia Elétrica UFES with the objective of obtaining indicators for evaluating the dropout rates and academic performance of students in the Electrical Engineering course at UFES. In this context, data analysis tools like Google Colab were used. The analysis methodologies and the results obtained are presented, as well as the conclusions about the observed academic profile.

Keywords: Dropout rates. Academic performance. Data Analysis. Digital Tools. 